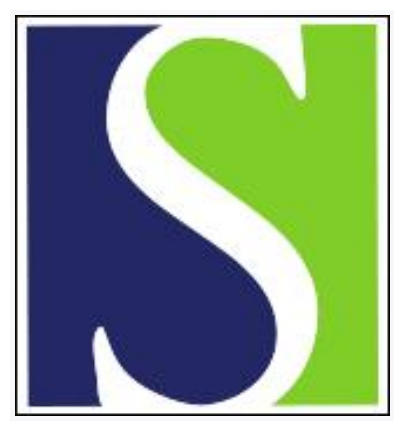

Scand J Work Environ Health 1985;11(5):381-387

https://doi.org/10.5271/sjweh.2209

Issue date: Oct 1985

Urine phthalate determinations as an index of occupational exposure to phthalic anhydride and di(2-ethylhexyl)phthalate. by Liss GM, Albro PW, Hartle RW, Stringer WT

This article in PubMed: www.ncbi.nlm.nih.gov/pubmed/4071004 


\title{
Urine phthalate determinations as an index of occupational exposure to phthalic anhydride and di(2-ethylhexyl)phthalate
}

\author{
by Gary M Liss, MD, ${ }^{1,3}$ Phillip W Albro, PhD, ${ }^{2}$ Richard W Hartle, MSPH, ${ }^{1}$ \\ William T Stringer, $\mathrm{MS}^{\dagger}$
}

\begin{abstract}
LISS GM, ALBRO PW, HARTLE RW, STRINGER WT. Urine phthalate determinations as an index of occupational exposure to phthalic anhydride and di(2-ethylhexyl)phthalate. Scand J Work Environ Health 11 (1985) 381-387. Although it has been estimated that over 600000 workers in the United States are exposed to di(2-ethylhexyl)phthalate (DEHP), an animal carcinogen, and that over 100000 are exposed to phthalic anhydride (PA), few data are available on levels of phthalates in biological fluids of these workers. For a determination of occupational exposure to PA and DEHP at a plant manufacturing DEHP from PA and 2-ethylhexanol, air samples were taken for PA and DEHP, and pre- and postshift urine samples were collected for the determination of total phthalates. Urine samples were obtained from 48 workers in jobs with high exposure to phthalates and from 47 workers in jobs with low exposure. The airborne concentrations of DEHP ranged from 20 to $4110 \mu \mathrm{g} / \mathrm{m}^{3}$, and the concentrations of PA ranged from 4 to $203 \mu \mathrm{g} / \mathrm{m}^{3}$. The most heavily exposed workers had the highest mean postshift urine phthalate concentration (geometric mean $7.6 \mathrm{nmol} / \mathrm{ml})(\mathrm{p}=0.015)$, and also the greatest mean increase $(4.4 \mathrm{nmol} / \mathrm{ml})$ in preshift to postshift urine phthalate levels. Twofold increases over the shift in urine phthalate concentration and postshift phthalate levels of greater than $10 \mathrm{nmol} / \mathrm{ml}$ were observed in $8(25 \%)$ of 32 chemical operators, but in none of 52 other workers. These data suggest that measurement of urine phthalate levels may have utility for monitoring the exposure of workers manufacturing or using PA.
\end{abstract}

Key terms: phthalates, plasticizers, biological monitoring.

Di(2-ethylhexyl)phthalate (DEHP) (figure 1) is a major feedstock chemical in the plastics industry. Estimated production of this compound in the United States in 1977 was 176450 metric tons (18). By far the largest use of DEHP is as a plasticizer for materials such as polyvinyl chloride. The addition of DEHP to polyvinyl chloride confers the desired characteristics of flexibility and softness to the polymer $(4,8)$. The number of workers in the United States potentially exposed to DEHP was estimated in 1980 to be approximately 625000 (16).

Phthalic anhydride (PA) (figure 1) is used as a curing agent for epoxies and as a starting material in the manufacture of DEHP and other phthalates. Exposure to PA has been shown previously to produce irritation of the respiratory tract, as well as occupational asthma $(5,13)$. In 1980 there were approximately 142000 workers in the United States potentially exposed to PA (17).

Historically, published reviews concerning the phthalate esters (4) and DEHP (23) have discussed the low order of acute toxicity of these compounds. More

\footnotetext{
1 Division of Surveillance, Hazard Evaluations, and Field Studies; National Institute for Occupational Safety and Health; Cincinnati, Ohio; United States.

2 Laboratory of Molecular Biophysics, National Institute of Environmental Health Sciences, Research Triangle Park, North Carolina, United States.

${ }^{3}$ Current address same as for reprint requests.
}

Reprint requests to: Dr GM Liss, Health Studies Service, Special Studies and Services Branch, Ontario Ministry of Labour, 400 University Avenue, $8^{\text {th }}$ Floor, Toronto, Ontario, M7A IT7, Canada. recently, however, observations that (i) considerable amounts of phthalate esters have been incorporated into blood storage bags made of polyvinyl chloride and into other plastic devices with medical applications and that (ii) patients can absorb and retain phthalates from these sources have focused attention on the possible chronic effects of exposure to these compounds (23). In 1970 DEHP was detected in the tissues and organs of two deceased patients who had previously received transfusions (9). The potential for DEHP accumulation in blood (10) and red cell concentrates (20) was found to be high during the storage of these materials in bags made of polyvinyl chloride.

The testing of DEHP for carcinogenesis by the National Toxicology Program (18) showed dose-related increased incidences of hepatocellular carcinoma in female rats and in both male and female mice. The International Agency for Research on Cancer concluded that there was no adequate epidemiologic study on DEHP available but that there was sufficient evidence for carcinogenicity in animals (8); thus DEHP should be considered a potential human carcinogen. A recent case-referent study from Italy found elevated risks for lung cancer in subjects with employment at a factory manufacturing acetylene, PA, DEHP, and other phthalates in comparison to workers with no occupational exposures to these compounds (21).

Although limited data have been obtained on concentrations of DEHP or phthalates in body fluids (7) (and reviewed in references 8 and 11) of patients who received hemodialysis and transfusions, there are few data available on biological levels of phthalates in 
<smiles>O=C1O[O+]C2=C1c1ccccc12</smiles>

PHTHALIC ANHYDRIDE (PA)



2 - ETHYLHEXANOL

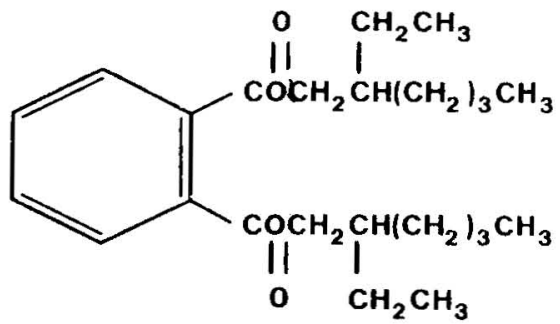

DI(2 - ETHYLHEXYL) PHTHALATE (DEHP)

Figure 1. Chemical structure of di(2-ethylhexyl)phthalate and phthalic anhydride.

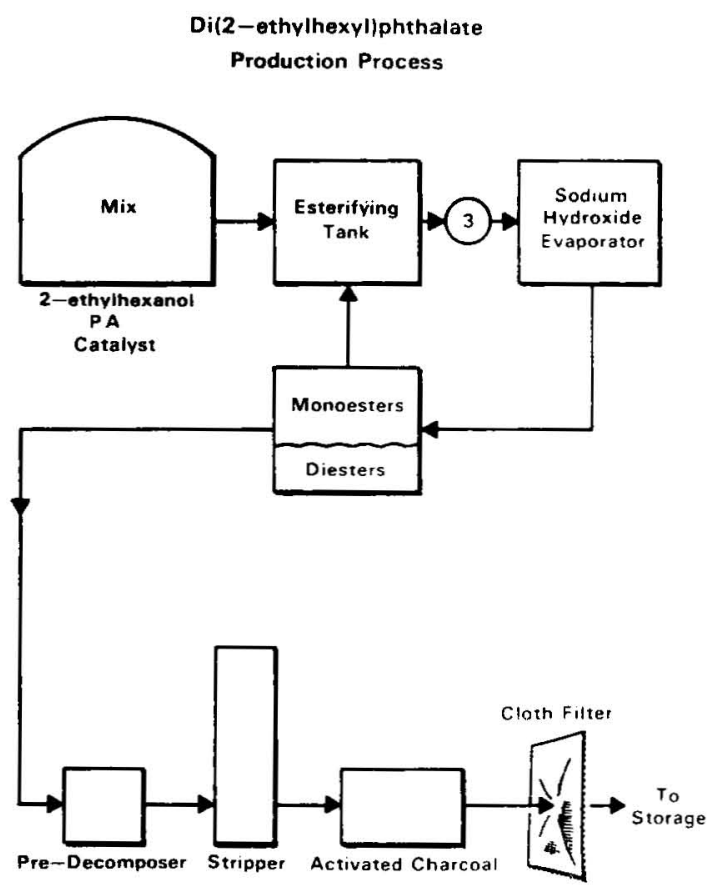

Figure 2. Production process for di(2-ethylhexyl)phthalate.

workers with occupational exposure to these compounds. A German study found DEHP in concentrations of up to $7.5 \mathrm{mg} / \mathrm{l}(19.2 \mathrm{nmol} / \mathrm{ml})$ in urine from workers engaged in manufacturing DEHP and up to $1.5 \mathrm{mg} / \mathrm{l}(3.8 \mathrm{nmol} / \mathrm{ml})$ in referents (22). However, no information on laboratory background (blank levels) and criteria for identification were provided in that report.

During an environmental study and cross-sectional evaluation of morbidity in a plant manufacturing DEHP from PA and 2-ethylhexanol (12), we obtained air samples and collected urine specimens for determining total phthalate concentrations. This report on that investigation is intended (i) to describe environmental exposures to phthalates in this plant and (ii) to investigate the utility of measuring total urinary phthalate concentrations as a tool for the biological monitoring of workers exposed occupationally to PA and DEHP.

\section{Methods and materials}

\section{Process description}

The PA and DEHP production areas in the study plant are located out-of-doors and are monitored from a common, enclosed control room. PA is produced from a reaction of o-xylene with air. DEHP is produced in an adjacent area by a continuous-flow operation involving the esterification of 2-ethylhexanol with PA in the presence of a catalyst (figure 2). Approximately $30 \%$ of the PA produced at the plant is used on-site in the production of DEHP, while the remainder is pumped to tank cars and trucks and sold for use elsewhere.

In 1981, a batch ester plant (BEP) came on-line at this site. The plant has the capacity to produce DEHP and other phthalates. Processes for the production of DEHP in this plant are essentially identical to those used in the PA/DEHP plant, except that they are batch in nature rather than continuous.

In addition to the shift supervisor, four operators work each shift in the PA/DEHP plant, two on the DEHP side and two on the PA side. Due to the close proximity of the PA and DEHP production areas, both PA and DEHP chemical operators and maintenance workers may be exposed to DEHP and PA. The greatest potential for the exposure of operators to phthal- 
ates appeared to exist during sample acquisition, especially in the PA/DEHP plant, where sample ports are opened and flushed and sample containers are filled by hand. For the PA operators duties with the highest potential for exposure would include sample acquisition and occasional involvement in the dumping of the PA sublimator boxes. Tank farm operators are concerned primarily with loading tank trucks with DEHP and PA (resulting in multiple opportunities for exposures to both compounds). The use of respiratory protection is required, and local exhaust ventilation is utilized at the loading ports.

\section{Environmental evaluation}

To determine exposure to airborne DEHP and PA, personal sampling pumps calibrated at $1.0 \mathrm{l} / \mathrm{min}$ were attached to the employees' belts and connected to 37-mm diameter cassettes containing Millipore "AA" filters, which were attached to the collar. Air was then drawn through the filters for the duration of the workshift. Laboratory analysis of PA involved high-pressure liquid chromatography, according to the method (S-179) published by the National Institute for Occupational Safety and Health (NIOSH) (15). The lowest limit of detection for PA was $1.5 \mu \mathrm{g} / \mathrm{sample}$. DEHP samples were analyzed according to NIOSH method S-40 (14). The analytical limit of detection was $10 \mu \mathrm{g} /$ sample.

\section{Exposure classification system}

A system for the classification of jobs and departments based on the relative ranking of exposure to DEHP (and PA) was developed by consensus during joint discussions involving the investigators, the local union president, a corporate industrial hygienist, and the corporate environmental and safety manager. This initial classification was then modified slightly to take into consideration the industrial hygiene data derived during the study. The object was to divide job titles into two major groups: one likely (group 1) and one unlikely (group 2) to be exposed to DEHP and PA. Group 1 (likely or higher exposure) included the chemical operators (DEHP, PA and BEP operators), mechanics spending most of their time in the PA/ DEHP area, and tank farm operators. Group 2 (unlikely or lower exposure) included storekeepers; wastewater operators; boiler operators; quality control operators; instrument technicians; first-line supervisors; and employees involved in administration, safety, engineering, and accounting work. Group 1 was further subdivided according to presence (group 1-A) or absence (group 1-B) of detectable concentrations of airborne PA in personal air samples on the days of the urine sampling.

\section{Urine samples for phthalate determination}

In an attempt to assess accumulation or absorption of phthalate over a single workshift, employees were evaluated, where possible, on the first day back to work following a period of nonexposure. For logistical reasons, the fourth shift was, however, assessed on the second day back to work after a weekend. Personal air sampling was performed simultaneously with the urine sampling. Pre- and postshift urine samples (each of 10 to $50 \mathrm{ml}$ in volume) were collected in $100-\mathrm{ml}$ glass bottles that had been previously washed, sequential$\mathrm{ly}$, with a cleaning solution of chromic and sulfuric acid, with soap and water, and with distillepd water. The workers produced the urine samples at a NIOSH medical testing trailer that was parked approximately one-quarter of a mile (about $0.4 \mathrm{~km}$ ) from the production area. No plastic bottles were used. The tops were screw-capped with paper lining. The bottle mouths were covered with acetone-rinsed aluminum foil prior to the screwing on of the caps. The bottled specimens were coded and shipped frozen for laboratory analysis. The total phthalate concentration in urine was determined by gas chromatography after hydrolysis and conversion to dimethyl phthalate, as previously described (3). Historically, the lowest concentration observed in human urine at this laboratory had been $0.4 \mathrm{nmol} / \mathrm{ml}$; the highest was $250 \mathrm{nmol} / \mathrm{ml}$ in leukemia patients receiving multiple platelet transfusions. The highest value observed at the laboratory in "unexposed" persons was $9 \mathrm{nmol} / \mathrm{ml}$. To assess the possible contribution of any phthalate that might be available in the bottles to the concentrations of phthalate measured in the urine, phthalate esters were extracted with methylene chloride $(2 \mathrm{ml})$ from three randomly selected, identically cleaned bottles. The extracts were analyzed for phthalate (dimethyl through dioctyl) by gas chromatography on OV-3 (1).

A number of urine samples (those with the highest total phthalate) were also assayed for DEHP and for specific DEHP metabolites, including monoethylhexyl phthalate (MEHP) by gas chromatography-mass spectrometry as previously described (2). From what little is known about the metabolism of DEHP by humans $(7,19)$, one would expect monoethylhexyl phthalate to be a major component of the complex mixture of urinary metabolites. Specific gravity of the urine samples was determined with an American optical temperature compensated TS meter, series B. Deionized water, finally purified by passage through charcoal, was put through the complete analytical procedure for total phthalate as a check on reagent and general laboratory background.

\section{Statistical analysis}

Variables with skewed distributions (preshift and postshift urine phthalate concentrations) were log-transformed before the analysis. The pre- to postshift differences were not skewed and thus were not transformed. Data from the three groups (1-A, 1-B, and 2) were compared with an analysis of variance. The significance of pairwise comparisons was assessed with 
Table 1. Summary of phthalic anhydride exposure concentrations.

\begin{tabular}{lccc}
\hline Operation & $\begin{array}{c}\text { Number of } \\
\text { samples }^{\mathrm{a}}\end{array}$ & $\begin{array}{c}\mathrm{Range}^{\mathrm{b}} \\
\left(\mu \mathrm{g} / \mathrm{m}^{3}\right)\end{array}$ & $\begin{array}{c}\mathrm{Mean} \\
\left(\mu \mathrm{g} / \mathrm{m}^{3}\right)\end{array}$ \\
\hline $\begin{array}{l}\text { Di(2ethylhexyl)phthalate } \\
\text { production }\end{array}$ & $8(5)$ & $6-102$ & 38 \\
$\begin{array}{l}\text { Phthalic anhydride } \\
\text { production }\end{array}$ & $6(4)$ & $4-187$ & 53 \\
$\begin{array}{l}\text { Phthalic anhydride and } \\
\text { di(2-ethylhexyl)phthalate }\end{array}$ & $5(4)$ & $11-26$ & 24 \\
$\begin{array}{l}\text { maintenance } \\
\begin{array}{l}\text { Batch ester plant } \\
\text { production }\end{array}\end{array}$ & $8(7)$ & $5-21$ & 11 \\
$\begin{array}{l}\text { Batch ester plant } \\
\text { maintenance }\end{array}$ & $3(2)$ & $21-44$ & 33 \\
\begin{tabular}{l} 
Tank farm \\
\hline
\end{tabular} & $6(6)$ & $17-203$ & 79 \\
\hline
\end{tabular}

a Number of samples above the analytical detection limit in parentheses.

b Determined from those samples above the analytical detection limit.

Table 2. Urinary phthalate concentrations by exposure group.

\begin{tabular}{lccc}
\hline Type of sample & $\begin{array}{c}\text { Group } \\
1 \cdot \mathrm{A}^{\mathrm{a}}\end{array}$ & $\begin{array}{c}\text { Group } \\
1 \cdot \mathrm{B}^{\mathrm{b}}\end{array}$ & $\begin{array}{c}\text { Group } \\
2^{\mathrm{c}}\end{array}$ \\
\hline Preshift & \multicolumn{3}{c}{} \\
$\quad$ Number of samples & 26 & 20 & 41 \\
Mean (nmol/ml) & 5.6 & 4.9 & 6.4 \\
$\quad$ Standard deviation & 3.4 & 6.1 & 6.7 \\
$\quad$ Range (nmol/ml) & \multicolumn{2}{c}{$0.6-28.9$} & $1.2-31.2$ \\
Postshift & \multicolumn{4}{c}{} \\
$\quad$ Number of samples & 27 & 19 & 40 \\
Mean (nmol/ml) & 9.9 & 6.8 & 5.9 \\
Standard deviation & 8.7 & 8.1 & 4.8 \\
Range (nmol/ml) & \multicolumn{2}{c}{$1.1-44.3$} & $1-28.2$ \\
\hline
\end{tabular}

a Group 1-A = higher exposure group with detectable airborne phthalic anhydride in personal sample.

b Group 1-B $=$ higher exposure group without detectable airborne phthalic anhydride in personal sample.

c Group 2 = lower exposure group.

Tukey's test. The mean pre- to postshift changes were tested for significance from zero by the paired t-test. The relationship of airborne exposure to PA with the postshift urinary phthalate concentration or with the pre- to postshift change in the urinary phthalate concentration was assessed by Spearman's rank correlation coefficient. The significance of the categorical data was assessed with Fisher's exact test.

\section{Results}

\section{Environmental evaluation}

Air samples were obtained over five shifts for the determination of exposure to DEHP and PA. Of 50 personal samples obtained for DEHP, six contained levels above the analytical limit of detection $(10 \mu \mathrm{g} /$ sample), the time-weighted average concentrations ranging from 20 to $4110 \mu \mathrm{g} / \mathrm{m}^{3}$ (mean $71 \mu \mathrm{g} / \mathrm{m}^{3}$ ). These high levels were obtained from one maintenance worker (engaged in the repair of the DEHP esterifier) and from five chemical operators (two BEP operators and three DEHP operators). Exposures to measurable

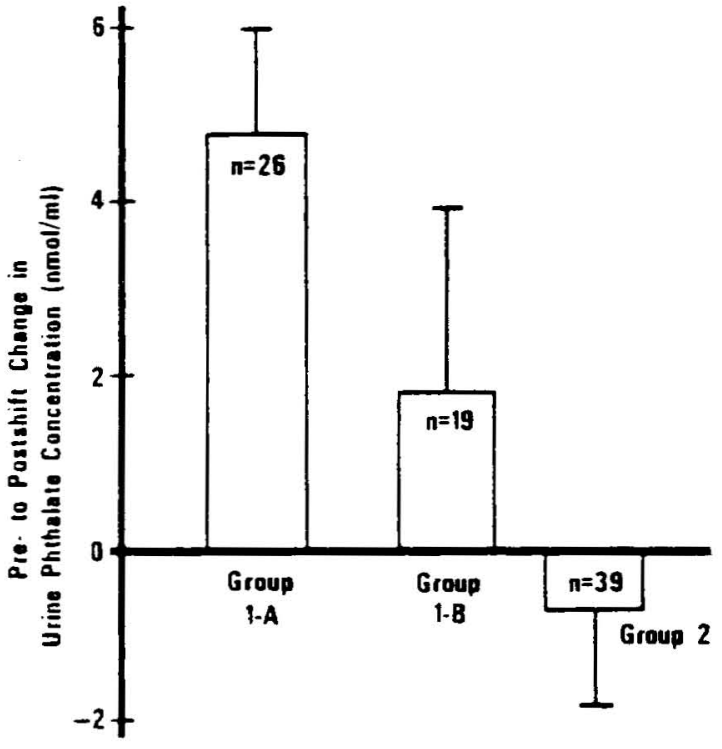

EXPOSURE GROUP

Figure 3. Pre- to postshift change in the urinary phthalate concentrations of the exposure groups. Results are the means and standard errors of the means. Numerals in each bar represent number of subjects with both pre-and postshift urinary phthalate determinations. The statistical interpretation can be found in the text. (Group 1-A = higher exposure group with detectable airborne phthalic anhydride in personal sample, group $1-\mathrm{B}=$ higher exposure group without detectable airborne phthalic anhydride in personal sample, group $2=$ lower exposure group)

quantities of PA were found in all the manufacturing processes for at least a portion of the workers sampled, the levels ranging from 4 to $203 \mu \mathrm{g} / \mathrm{m}^{3}$ (table 1).

\section{Participants}

The 95 employees who provided urine specimens included 66 from the bargaining unit (representing $90 \%$ participation) and 29 salaried personnel (representing $42 \%$ participation). All employees had been in their current job for at least six months.

Of the employees evaluated, 48 were in group 1 (workers in jobs likely to be exposed to PA and DEHP) and 47 were in group 2 (workers in jobs unlikely to be exposed). Of the 47 workers in the lower exposure group, five (11\%) had, for one year or longer, previously held jobs that have been classified in the "higher" exposed category (group 1). In the intergroup comparisons which follow, these five individuals have not been included.

\section{Urine phthalate concentrations}

No phthalate was detectable [limit of quantification $0.4 \mathrm{nmol} / \mathrm{ml}$ (3)] in the deionized, charcoal-treated water used as procedural blanks. The urine collection bottles contained trace levels of phthalate, such that, if all of that phthalate had been dissolved in $10 \mathrm{ml}$ of urine (a worst-case calculation), the maximum urine 
Table 3. Comparison of log-transformed pre- and postshift concentrations of the exposure groups.

\begin{tabular}{|c|c|c|c|c|c|}
\hline Type of sample & $\underset{1-A^{a}}{G r o u p}$ & $\underset{1-B^{b}}{G \text { Group }}$ & $\underset{2^{c}}{\text { Group }}$ & $p-$ Value $^{d}$ & $\begin{array}{c}\text { Significant } \\
\text { pairwise } \\
\text { comparisons }\end{array}$ \\
\hline $\begin{array}{l}\text { Preshift } \\
\text { Number of samples } \\
\text { Mean } \\
\text { Standard deviation }\end{array}$ & $\begin{array}{l}26 \\
0.67 \\
0.28\end{array}$ & $\begin{array}{l}20 \\
0.50 \\
0.40\end{array}$ & $\begin{array}{l}41 \\
0.65 \\
0.35\end{array}$ & 0.22 & $\begin{array}{c}\text { Not } \\
\text { significant }\end{array}$ \\
\hline $\begin{array}{l}\text { Postshift } \\
\text { Number of samples } \\
\text { Mean } \\
\text { Standard deviation }\end{array}$ & $\begin{array}{l}27 \\
0.88 \\
0.31\end{array}$ & $\begin{array}{l}19 \\
0.64 \\
0.38\end{array}$ & $\begin{array}{l}40 \\
0.68 \\
0.28\end{array}$ & 0.015 & $1-A$ vs $2 \& 1-A$ vs $1-B$ \\
\hline
\end{tabular}

level from this source would not have exceeded $0.017 \mathrm{nmol} / \mathrm{ml}$, a value below the limit of quantification of the total phthalate assay.

Results were not available for three pre- and four postshift samples because of the presence of substances interfering with the assay or because of failure of the subjects to provide samples. For the remaining samples, we determined the mean and ranges of the total urinary phthalate concentration for the pre- and postshift urine samples by exposure group (table 2).

The mean (log-transformed) urinary phthalate concentrations of the preshift samples did not differ among the exposure groups (table 3). The corresponding concentrations of the postshift samples differed significantly among the three groups and were greatest for group 1-A (geometric mean $7.6 \mathrm{nmol} / \mathrm{ml}$ ). There were also significant differences (figure 3 ) among the three groups with respect to pre- to postshift changes ( $p=0.043$ by analysis of variance). Pairwise comparisons showed that the pre- to postshift changes in group 1-A $(4.41 \mathrm{nmol} / \mathrm{ml})$ and group $2(-0.66 \mathrm{nmol} /$ $\mathrm{ml})$ were significantly different from each other at a probability level of 0.05 (Tukey's test). The mean value for the intrashift change in group $1-\mathrm{B}(1.95 \mathrm{nmol} / \mathrm{ml})$ was intermediate between the other two.

The mean pre- to postshift change in group 1-A [4.41 (SD 8.9) $\mathrm{nmol} / \mathrm{ml}$ ] was significantly different from zero ( $\mathrm{N}=26, \mathrm{p}=0.018$ by paired t-test); the mean change in group 1-B [1.95 (SD 10.2) $\mathrm{nmol} / \mathrm{ml}]$ was not significantly different from zero $(\mathrm{N}=19, \mathrm{p}=0.418)$; and the mean change in group 2 , a decrease of -0.66 (SD 5.6) $\mathrm{nmol} / \mathrm{ml}$, was also not significantly different from zero $(\mathrm{N}=39, \mathrm{p}=0.465)$.

A pattern similar to the mean intrashift increase in group 1-A, the mean increase of smaller magnitude in $1-B$, and the mean decrease in group 2 was observed when the urinary concentrations were corrected to a specific gravity of 1.024 . The laboratory did not find monoethylhexyl phthalate [a major metabolite of DEHP in the urine of humans exposed to DEHP by intravenous administration (19)] in these urine samples.

There was a weak positive correlation between personal exposure to airborne PA and the total urinary
Table 4. Employees showing substantial pre- to postshift increases in their urinary phthalate concentrations. ${ }^{\mathrm{a}}(\mathrm{PA}=$ phthalic anhydride, DEHP = di(2-ethylhexyl)phthalate, BEP = batch ester plant)

\begin{tabular}{lccl}
\hline $\begin{array}{l}\text { Case } \\
\text { number }\end{array}$ & $\begin{array}{c}\text { Preshift } \\
\text { phthalate } \\
\text { concentration } \\
\text { (nmol/ml) }\end{array}$ & $\begin{array}{c}\text { Postshift } \\
\text { phthalate } \\
\text { concentration } \\
\text { (nmol/ml) }\end{array}$ & Job title \\
\hline 0002 & 4.7 & 26.7 & PA operator \\
0040 & 4.9 & 44.3 & DEHP operator \\
0041 & 6.9 & 14.4 & DEHP operator \\
0047 & 6.8 & 30.4 & BEP operator \\
0052 & 2.1 & 18.8 & BEP operator \\
0055 & 4.9 & 22.6 & DEHP operator \\
0062 & 4.7 & 11.1 & BEP operator \\
0093 & 7.0 & 17.2 & PA operator \\
\hline
\end{tabular}

a Substantial increase: postshift concentration greater than twice (preshift concentration) and postshift concentration greater than $10 \mathrm{nmol} / \mathrm{ml}$.

phthalate concentration of the postshift samples $\left(r_{\mathrm{s}}=\right.$ 0.25 ), but there was no correlation between airborne exposure and the preshift to postshift change $\left(r_{s}=\right.$ 0.05 ). Neither did the urinary phthalate concentrations appear to correlate with the six detectable airborne DEHP concentrations.

To assess further which job titles exhibited substantial increases in the urinary phthalate level over the shift, we arbitrarily defined a "substantial" increase as a postshift value greater than two times the preshift value and a postshift value greater than $10 \mathrm{nmol} / \mathrm{ml}$. This cut-off was of the same order of magnitude as the highest value observed historically in laboratory personnel and was an order of magnitude greater than previously published values for "unexposed" persons (6). Eight employees were identified who met this double criterion; all eight were chemical operators (table 4$)$. Thus $8(25 \%)$ of 32 chemical operators with both pre- and postshift urine specimens available displayed a substantial increase in their urinary phthalate concentrations over the shift, while none of 52 nonchemical operators did $(\mathrm{p}=\mathbf{0 . 0 0 0 2 5}$, Fisher's exact test, one-tailed). Of these eight chemical operators, personal exposure data on the day of urine collection were available for six. PA was detected in air 
samples for four, the levels ranging from 6 to $102 \mu \mathrm{g} /$ $\mathrm{m}^{3}$, but for the other two the PA level was below the limit of detection (less than 4 and $3 \mu \mathrm{g} / \mathrm{m}^{3}$, respectively). The PA concentrations did not appear to be correlated with the urinary phthalate concentrations among these operators. DEHP was detected in the air samples of two of these eight operators.

The five highest postshift phthalate concentrations ( $>20 \mathrm{nmol} / \mathrm{ml}$ ) occurred in four chemical operators and in one salaried administrator who was unlikely to have worked near the reactors. The preshift phthalate concentration of this salaried employee was actually higher than his postshift value.

\section{Discussion}

A major aim of this study was to evaluate the utility of urinary phthalate concentrations as a means of assessing occupational exposure to DEHP or PA. We found significant differences in the postshift concentrations and in the pre- to postshift changes in total urinary phthalate concentration between employees working in jobs considered to be at high risk of exposure to DEHP and to PA, in comparison to those not at risk of such exposure. This difference was particularly marked in that group of workers who were found, through personal (breathing zone) air samples obtained on the day of the urine sampling, to be exposed to PA. Substantial pre- to postshift increases were limited to the chemical operators.

A number of observations suggest that the observed changes in the urinary phthalate concentrations were related to the occupational exposures of the workers. First, there were no differences between the preshift values of the "high" and "low" exposure groups; the mean preshift values of the unexposed workers, apparently reflecting background population exposure, were actually somewhat greater than those of the exposed group. Second, all of the substantial increases over the shift were found in chemical operators, who by observation (and environmental monitoring) were most likely to be exposed. Third, the changes and increases were the most marked for those workers with detectable airborne exposure to PA. Finally, we excluded, through the procedure of running blanks through the laboratory analysis, the possibility of some source of contamination during the urine collection process.

Those workers in job categories considered to be at high risk of exposure to PA and DEHP, but who did not have detectable exposure to airborne PA on the day of the urine sampling (group 1-B), had a mean preto postshift increase in urinary phthalate concentration intermediate in value between the other two groups (figure 3). This finding, plus (i) the fact that twofold increases in urinary phthalate levels occurred in some chemical operators who did, not have detectable airborne exposure to PA and (ii) the poor correlation between airborne and urinary phthalate concentrations, suggests that employees in group 1-B may have experienced phthalate exposure in the absence of detectable exposure to airborne PA or DEHP. This finding implies that these workers may either have experienced airborne exposure below our limits of detection or that they absorbed phthalates from a route other than inhalation, perhaps percutaneously or orally.

The study by Draviam et al (6) is the only previous report, of which we are aware, that has quantified total phthalate concentrations in urine from humans without known exposures. Draviam et al reported a mean urinary phthalate concentration of $0.99 \mathrm{nmol} / \mathrm{ml}$ in unexposed persons. Few data are available on phthalate concentrations in biological fluids of workers exposed to phthalates. Thiess \& Fleig (22) attempted to detect DEHP and possible metabolites in urine (and blood) from six exposed workers and from three unexposed personnel during a morbidity study of 101 workers employed in a DEHP production plant in Germany. The urine samples were processed by a modified method not described in detail. The DEHP levels reportedly ranged from $0.2 \mathrm{mg} / 1$ (limit of detection) to $7.5 \mathrm{mg} / 1(0.5$ to $19.2 \mathrm{nmol} / \mathrm{ml})$ in exposed workers and from 0.2 to $1.5 \mathrm{mg} / 1(0.5$ to $3.8 \mathrm{nmol} / \mathrm{ml})$ in the referents. The values for monoethylhexyl phthalate, the monoester metabolite of DEHP, were 61.6 and $34.3 \mathrm{ng} / \mathrm{d}(0.22$ and $0.12 \mathrm{nmol} / \mathrm{d})$ in the exposed workers and 57.7 and $42.4 \mathrm{ng} / \mathrm{d}(0.21$ and $0.15 \mathrm{nmol} /$ d) in the referents. The lack of experimental details concerning the analytical procedure makes evaluation of the significance of these numbers difficult. In workers in both the higher and lower exposure groups we found average urinary phthalate concentrations (both in pre- and postshift samples) that were substantially greater than those described by Draviam et al (6), but within the range reported by Thiess \& Fleig (22).

The findings that monoethylhexyl phthalate was not detected in these urine samples and that detectable DEHP was found in only a small number of airborne samples (including only two of eight operators with doublings of their urinary phthalate concentrations over the shift) suggest that the increased phthalate in the urine of this population likely resulted from absorbed PA rather than from DEHP. However, not all of the samples were analyzed for metabolites. Moreover, as there is presently no information available on the metabolic fate of DEHP in normal, healthy humans following either inhalation or topical exposure, we do not know how significant the metabolite monoethylhexyl phthalate should be in comparison to phthalic acid in normal humans. That monoethylhexyl phthalate is a major metabolite is known only for leukemia patients $(2,19)$. Although DEHP did not likely provide a major contribution to the total urinary phthalate excretion in our study, PA at this plant is a "marker" for exposure to DEHP because 
of the close proximity of all operators to both chemicals.

In summary, we have attempted to determine the utility of urinary phthalate determinations as a tool for the biological monitoring of groups exposed occupationally to phthalates. We found that substantial increases (doublings) in urinary phthalate levels, to postshift concentrations of over $10 \mathrm{nmol} / \mathrm{ml}$, were observed only in chemical operators. The current findings may not be widely applicable to workers using (in contrast to manufacturing) DEHP in situations where PA is not found. However, there is a suggestion of utility for these determinations in workers exposed to PA, with or without concomitant exposure to DEHP.

\section{Acknowledgments}

The authors would like to thank Dr P Landrigan for his helpful comments during the preparation of this manuscript.

\section{References}

1. Albro PW, Corbett JT. Distribution of di- and mono(2-ethylhexyl) phthalate in human plasma. Transfusion 18 (1978) 750-755.

2. Albro PW, Hass JR, Peck CC, Odom DG, Corbett JT, Bailey FJ, Blatt HE, Barrett BB. Identification of the metabolites of di-(2-ethylhexyl) phthalate in urine from the African Green Monkey. Drug Metab Dispos 9 (1981) $223-225$.

3. Albro PW, Jordan S, Corbett JT, Schroeder JL. Determination of total phthalate in urine by gas chromatography. Anal Chem 56 (1984) 247-250.

4. Autian J. Toxicity and health threats of phthalate esters: Review of the literature. Environ Health Perspect 4 (1973) 3-26.

5. Bernstein IL. Occupational asthma. Clin Chest Med 2 (1981) 255-272.

6. Draviam EJ, Kerkay J, Pearson KH. Separation and quantitation of urinary phthalates by HPLC. Anal Lett 13 (1980) 1137-1155.

7. Draviam EJ, Pearson KH, Kerkay J. Human metabolism of bis(2-ethylhexyl) phthalate. Anal Lett 15 (1982) $1729-1750$.

8. International Agency for Research on Cancer. Some industrial chemicals and dyestuffs. Lyon 1982, pp 269294. (IARC monographs on the evaluation of the carcinogenic risk of chemicals to humans, volume XXIX).
9. Jaeger RJ, Rubin RJ. Plasticizers from plastic devices: Extraction, metabolism and accumulation by biological systems. Science 170 (1970) 460-462.

10. Jaeger RJ, Rubin RJ. Migration of a phthalate ester plasticizer from polyvinyl chloride blood bags into stored human blood and its localization in human tissues. $\mathrm{N}$ Engl J Med 287 (1972) 1114-1118.

11. Lawrence WH, Tuell SF. Phthalate esters: The question of safety - An update. Clin Toxicol 15 (1979) 447-466.

12. Liss GM, Hartle RW. Health hazard evaluation report no HETA 82-032-1384. National Institute for Occupational Safety and Health, Cincinnati, OH 1983.

13. Maccia CA, Bernstein IL, Emmett EA, Brooks SM. In vitro demonstration of specific IgE in phthalic anydride hypersensitivity. Am Rev Respir Dis 113 (1976) 701704.

14. National Institute for Occupational Safety and Health. NIOSH manual of analytical methods. Volume 3. Cincinnati, OH 1977. (DHEW (NIOSH) publication no 77-157-C).

15. National Institute for Occupational Safety and Health. NIOSH manual of analytical methods. Volume 2. Cincinnati, OH 1977. (DHEW (NIOSH) publication no 77-157-B).

16. National Institute for Occupational Safety and Health. Projected number of occupational exposures to chemical and physical hazards. Cincinnati, OH 1980, p 64.

17. National Institute for Occupational Safety and Health. National occupational hazards survey, 1972-1974. Cincinnati, OH 1980 (Updated as of August 1980).

18. National Toxicology Program. Carcinogenesis bioassay of di-(2-ethylhexyl)phthalate. Research Triangle Park, NC 1981. (NTP, DHHS publication no (NIH) 81-1773).

19. Peck CC, Albro PW. The toxic potential of the plasticizer di-2-ethylhexyl phthalate in the context of its disposition and metabolism in primates and man. Environ Health Perspect 45 (1982) 11-17.

20. Peck CC, Odom DG, Friedman HI, Albro PW, Hass JR, Brady JT, Jess DA. Di-2-ethylhexyl phthalate (DEHP) and mono-2-ethylhexyl phthalate accumulation in whole blood and red cell concentrates. Transfusion 18 (1979) 53-62.

21. Riboli E, Edoardo SM, Berrino F, Merisi A. Mortality from lung cancer in an acetylene and phthalic anhydride plant: A case-referent study. Scand J Work Environ Health 9 (1983) 455-462.

22. Thiess AM, Fleig I. Study on the morbidity of workers exposed to di-2-ethylhexyl phthalate. Zentralbi Arbeitsmed Arbeitssch Prophyl 28 (1978) 351-355.

23. Thomas JA, Darby TD, Wallin RF, Garvin PJ, Martis L. A review of the biological effects of di-(2-ethylhexyl)phthalate. Toxicol Appl Pharmacol 45 (1978) $1-27$.

Received for publication: 11 June 1984 